\title{
Factors associated with neonatal near-miss in selected hospitals of Gamo and Gofa zones, southern Ethiopia: nested case- control study
}

\author{
Abera Mersha* (1D, Agegnehu Bante and Shitaye Shibiru
}

\begin{abstract}
Background: To scale up a comprehensive way of implementation to reduce neonatal mortality evaluation of factors for neonatal near-miss cases is very important. Certain studies were done in assessing near-miss cases, but they failed in identifying the proximate factors affecting profoundly. So, this study is to fill those gaps in the aforementioned studies, in assessing the factors affecting neonatal near-miss cases.

Methods: A nested case-control study was conducted in selected three Hospitals of Gamo and Gofa Zones, Southern Ethiopia from April 5, 2018, to March 5, 2019. The structured standard tool was used to identify neonatal near-miss cases. Data were entered into Epi data version 3.1 and exported to Stata version 15 for analysis. A conditional logistic regression model was used to identify factors associated with near-miss cases. The goodness of fit was tested by a log-likelihood ratio (LR). In this study $P$-value $<0.05$ was considered to declare a result as a statistically significant association.

Results: In this study 121 neonatal near-miss cases, and 363 controls were involved. The identified factors that affect neonatal near-miss were multiparty $(\mathrm{AOR}=3.81,95 \% \mathrm{Cl}: 1.72,8.42)$, antenatal care follow up $(\mathrm{AOR}=0.02$, $95 \% \mathrm{Cl}: 0.01,0.05)$, premature rupture of membrane ( $\mathrm{AOR}=3.40,95 \% \mathrm{Cl}: 1.53,7.55)$, non-vertex presentation $(\mathrm{AOR}=$ $2.83,95 \% \mathrm{Cl}: 1.44,5.58$ ), and cesarean delivery ( $\mathrm{AOR}=4.89,95 \% \mathrm{Cl}: 2.34,10.24)$.

Conclusions: Those identified factors are better should be intervened. Strengthening antenatal care services by providing appropriate information for the mother and counseling about the consequences of multiparty and providing information on family planning. There is a need to identify, screen and critical follow high-risk mothers and give immediate and appropriate intervention as early as possible.
\end{abstract}

Keywords: Neonatal near-miss, Nested case-control study, Selected hospitals, Gamo and Gofa zones, Southern Ethiopia

\section{Background}

Globally, the neonatal mortality rate was decreased to 18 per 1000 live births and as indicated in many studies the main causes of neonatal deaths were preterm birth, intrapartum related complications, and sepsis [1-5]. In spite of developed nations, neonatal morbidity, and mortality rates remained high in resource-limited countries. It is projected that the number of survivors from a

\footnotetext{
* Correspondence: mershaabera@gmail.com

Department of Nursing, College of Medicine and Health Sciences, Arba Minch University, Arba Minch, Ethiopia
}

"neonatal near-miss" event is three to six times higher than the number of neonatal deaths [6].

Neonatal mortality is the utmost in resource-limited countries $[1,2]$. Each year, at least 1.16 million African babies die in the neonatal period. Thirty-eight percent (38\%) of babies in sub-Saharan Africa die of infections, mainly after seven days postpartum [7]. In Ethiopia, greater than 3/5th of infants and 2/5th of under-five deaths were neonatal deaths [8]. Based on, 2019Ethiopia Mini Demographic Health Survey report, 30 babies die per thousand live births [9].

(c) The Author(s). 2019 Open Access This article is distributed under the terms of the Creative Commons Attribution 4.0 International License (http://creativecommons.org/licenses/by/4.0/), which permits unrestricted use, distribution, and 
A substantial proportion of this neonatal mortality could be banned by the appropriate management of the neonate presenting life-threatening complications (neonatal near-miss) [10]. Assessing neonatal near-miss (NNM) cases give an all-inclusive assessment of risk factors, instant outcomes and predictive factors in neonates delivered from mother with different obstetric complications [11]. The use of the near-miss approach in neonatal health is a new idea in the direction of a pioneering tool to improve the quality of perinatal care [12]. The NNM approach provided information that could be valuable to sightsee the quality of care issues and set priorities for in-depth assessments and health care improvements in newborn health $[10,12,13]$. Discussions of morbidity are better accepted than death case reviews by health care teams. Thus, the quality of care would improve. There is an expectation of the development of prospective surveillance processes of severe neonatal morbidity [14].

Evidence showed that the NNM rate was higher than the neonatal mortality rate; increasing 2.6 to 8 fold [10, $12,15,16]$. The incidence of neonatal near-miss cases was ranged from 21.4 to 85.5 per 1000 live births [10-12, 1519]. Different studies suggested the majority of neonatal near-miss cases were caused by respiratory dysfunction/ failure, immunologic dysfunction/ failure, infections, central nervous system dysfunction/failure, birth asphyxia and very low birth weight $[11,20]$. Compared to the neonatal mortality rate, more cases of NNM were observed among obstetric cases in which asphyxia, trauma or antepartum hemorrhage had occurred [11, 15].

Based on previous shreds of evidence Global Maternal Child Survival Program gives attention to newborns in Ethiopia. The package ropes the government of Ethiopia to improve community-based maternal neonatal and child health $(\mathrm{MNCH})$ services to upsurge health-seeking behaviors; increases the delivery of eminence newborn care practices including management of newborn sepsis; and strengthens the supportive systems with a focus on district capacity building [21]. This program is underway, but to scale up a comprehensive way of implementation to reduce neonatal mortality evaluating determinants for NNM cases is very important. Some studies were done in assessing NNM cases, but they failed in identifying the proximate factors affecting intensely. So, this study is to fill those gaps of the aforementioned studies, in assessing the factors affecting NNM cases in selected Hospitals of Gamo and Gofa Zones, Southern Ethiopia.

\section{Methods}

\section{Study setting and period}

This study was conducted in selected three Hospitals of Gamo and Gofa Zones, Southern Ethiopia from April 5, 2018, to March 5, 2019. Gamo and Gofa are Zones within the South Nations, Nationalities and Peoples' Region (SNNPR) of Ethiopia. There are seven hospitals in Gamo and Gofa Zones but the study was done in selected three hospitals (Arba Minch General Hospital (AMGH), Sawla General Hospital (SGH) and Chencha Primary Hospital $(\mathrm{CPH})$ ). The total population of the study area is 2,019,687. The estimated number of women of reproductive age (15-49) is 470,587 from this, the estimated number of delivery is 69,881 and the estimated number of live birth is 69,881 . In Gamo and Gofa Zones, the skilled delivery rate is $51.2 \%[22,23]$.

\section{Study design}

A nested case-control study matched for sex and study setting (hospitals) were employed to meet the objectives.

\section{Selection of cases and controls}

The neonatal near-miss cases were identified by using standard definition, and appropriate criteria and defined as the presence of at least one pragmatic marker or management severity criteria $[14,19]$. The cases were matched for sex and study setting (hospitals) with controls that for each case three controls with similar sex groups and study settings were selected.

\section{Exclusion criteria}

Multiple pregnancies, neonatal deaths, and neonates who were referred from other health care institutions that were out of the study hospitals were excluded.

\section{Sample size determination}

The sample size was computed by using sample size determination in an unmatched case-control study in the Epi info7 software Stat Cal. The following assumptions were considered: $95 \%$ level of confidence, power of $80 \%$, the ratio of cases to control 1:3 and percent of controls exposed 15.8 and percent of cases with exposure 5.4. The percent of cases and controls were taken from the study conducted in northeastern Brazil that the most determinate variables for the neonatal near-miss were maternal age greater than 35 or advanced age [24]. Base on the above assumptions the estimated sample size was 110 cases and 330 controls. After considering the nonresponse of $10 \%$, the final sample size used for this study was 121 cases and 363 controls.

\section{Data collection method}

A pre-tested, structured interviewer-administered questionnaire and standard abstraction checklist to review data from medical records were used to collect the data. The standardized data abstraction form developed by the London School of Hygiene and Tropical Medicine (LSHTM) and its partners in multi-country nearmiss projects in Francophone Africa, the World Health 
Organization (WHO) Multi-Country Survey Project on severe maternal morbidity and the Unmet Obstetric Need (UON) projects led by the Institute of Tropical Medicine in Antwerp [25] were used to abstract pertinent information (Additional file 1). Neonates who experienced neonatal near-miss cases were identified by well-trained six diploma holders midwives and supervised by two MSc holder nurses. The data were collected from the delivery ward, postnatal ward and neonatal intensive care unit (NICU) of each hospital.

\section{Criteria's to identify near-miss cases}

The description of the criteria to identify neonatal nearmiss cases were stated in detail below (Table 1).

\section{Data quality control}

To ensure the quality of the data, the questionnaires in the local language were used to collect the information from the study participants. All health care workers working in the delivery ward, postnatal ward, and neonatal intensive care unit in each participating hospital were also sensitized to the issue so that they were informed the enumerators when they suspected near-miss cases. Besides, the inclusion criteria for the neonatal near-miss was printed and posted on the wall of each ward at all participating hospital. The data collectors were daily visits to the delivery ward, postnatal ward and NICU to check for potential cases. The data collectors were trained to standardize methods and ensure the consistency of data collection. Handy and frequent supervision of the questionnaire was made to ensure completeness and consistency.

\section{Data analysis and processing}

Data were coded and entered into Epi data version 3.1 and then exported to Stata version 15 for analysis. The data were cleaned before analysis. Bivariate analysis was done by using a binary logistic regression model to see the association between each independent variable and neonatal near-miss cases. The goodness of fit was tested by a log-likelihood ratio (LR). To include the variables into the final model $P<0.25$ in the bivariate analysis, and context point of view were considered. A conditional logistic regression model was used to ascertain the independent effect. Multi co-linearity was checked by collinearity statistics (Variance inflation factor and Tolerance). A crude and adjusted odds ratio with $95 \% \mathrm{CI}$ was estimated to identify factors affecting NNM cases. In this study $P$ value $<0.05$ was considered to declare a result as a statistically significant association.

\section{Results}

\section{Socio-demographic and economic characteristics}

In these 121 cases and 363 controls were involved with a response rate of $100 \%$ for both cases, and controls, as it was a nested case-control study. The mean age in years and a standard deviation of neonate's mother was $29.95 \pm 4.12$ for cases and $27.61 \pm 6.65$ for controls. The majority (96.7\%) of the neonate's mother for cases and 361 (99.4\%) for controls were married. Of the respondents, $104(86.0 \%)$ for cases and 301 (82.9\%) for controls were Gamo ethnicity. Regarding the educational status of neonates mother 66 (54.5\%) for cases and 207 (57.0\%) for controls had secondary education (grade 9 to 12). Fifty (41.3\%) of neonates' fathers had the educational status of secondary for cases and 162 $(44.6 \%)$ for controls. Out of neonates mother 71(58.7\%), and 45(37.2\%) had orthodox, and protestant religion followers for cases and $172(47.4 \%)$ and $180(49.6 \%)$ for controls respectively. Twenty-nine (24.0\%) of the neonates' mother was a housewife for cases and 214 (59.0\%) for controls. Of the respondents, $79(65.3 \%)$ for cases and 266(73.3\%) for controls were urban residents (Table 2).

\section{Maternal and child health, and obstetric factors}

Of the neonates' mother, 101(83.5\%) for cases and $196(54.0 \%)$ for controls had multipara (birth order $\geq 2$ ). Five $(5.0 \%)$ of the respondents had a history of stillbirth, and 5(5.0\%) had a history of abortion for cases, and 38(19.4\%) and 39(19.9\%) for controls respectively. Regarding birth interval, 37(36.6\%) of the mothers of the neonates were birth inter of 24-48 months for cases and $136(69.4 \%)$ for controls. Thirty-two (31.7\%) of the neonates' mother had a history of neonatal death for cases and $49(25.0 \%)$ for controls. Of the neonates' mothers, 54 (44.6\%) had antenatal care (ANC) follow

Table 1 Criteria to identify neonatal near-miss cases in selected Hospitals of Gamo and Gofa Zones, Southern Ethiopia, 2018/9

\begin{tabular}{ll}
\hline Criteria & Descriptions \\
\hline $\begin{array}{l}\text { Pragmatic markers } \\
\text { criteria }\end{array}$ & $\begin{array}{l}\text { It is the severity of a criterion that is used to classify neonate as a neonatal near-miss. It includes birth weight }<1750 \mathrm{~g}, \\
\text { Apgar score }<7 \text { at } 5 \mathrm{~min} \text { and } \mathrm{GA}<33 \text { weeks [14]. }\end{array}$ \\
$\begin{array}{l}\text { Management severity } \\
\text { criteria }\end{array}$ & $\begin{array}{l}\text { It is a criterion based on the management base. It includes parenteral antibiotic therapy, nasal continuous positive airway } \\
\text { pressure (CPAP), any intubation, and phototherapy within 24 } \mathrm{h} \text {. of life, cardiopulmonary resuscitation (CPR), use of } \\
\text { vasoactive drugs, anticonvulsants, surfactant, blood products, steroids for the treatment of refractory hypoglycemia, surgery, } \\
\text { use of antenatal steroid, use of parenteral nutrition, identification of congenital malformation according to the ICD-10 if } \\
\text { considered a near-miss case by another criterion and admission to the NICU [14]. }\end{array}$ \\
\hline
\end{tabular}


Table 2 Socio-demographic and economic characteristics of study participants in selected hospitals of Gamo and Gofa Zones, Southern Ethiopia, 2018/9

\begin{tabular}{|c|c|c|c|c|}
\hline Characteristics & Cases $(n=121)$ & Control $(n=363)$ & $\operatorname{COR}(95 \% \mathrm{Cl})$ & $P$-value \\
\hline \multicolumn{5}{|l|}{ Age } \\
\hline $15-24$ & $6(5.0)$ & $114(31.4)$ & 1 & \\
\hline $25-34$ & $92(76.0)$ & $188(51.8)$ & $9.29(3.94,21.93)$ & $<0.0001$ \\
\hline$\geq 35$ & $23(19.0)$ & $61(16.8)$ & $7.16(2.77,18.54)$ & $<0.0001$ \\
\hline \multicolumn{5}{|l|}{ Marital status } \\
\hline Married & $117(96.7)$ & $361(99.4)$ & $0.16(0.03,0.89)$ & 0.04 \\
\hline Other ${ }^{\mathrm{a}}$ & $4(3.3)$ & $2(0.6)$ & 1 & \\
\hline \multicolumn{5}{|l|}{ Ethnicity } \\
\hline Gamo & $104(86.0)$ & $301(82.9)$ & $1.56(0.70,3.45)$ & 0.28 \\
\hline Gofa & $9(7.4)$ & $26(7.2)$ & $1.56(0.53,4.58)$ & 0.42 \\
\hline Othert & $8(6.6)$ & $36(9.9)$ & 1 & \\
\hline \multicolumn{5}{|c|}{ Educational status of the mother } \\
\hline No formal education & $12(9.9)$ & $32(8.8)$ & 1 & \\
\hline Primary (1-8) & $21(17.4)$ & $56(15.4)$ & $1.00(0.44,2.29)$ & 1.00 \\
\hline Secondary (9-12) & $66(54.5)$ & $207(57.0)$ & $0.85(0.41,1.75)$ & 0.66 \\
\hline College and above & $22(18.2)$ & $68(18.7)$ & $0.86(0.38,1.96)$ & 0.72 \\
\hline \multicolumn{5}{|l|}{ Occupation of the mother } \\
\hline Housewife & $29(24.0)$ & $214(59.0)$ & $1.69(0.38,7.53)$ & 0.49 \\
\hline Merchant & $75(62.0)$ & $42(11.6)$ & $22.32(5.04,98.94)$ & $<0.0001$ \\
\hline Government employer & $15(12.4)$ & $82(22.6)$ & $2.29(0.49,10.69)$ & 0.29 \\
\hline Other ${ }^{\oplus}$ & $2(1.7)$ & $25(6.9)$ & 1 & \\
\hline \multicolumn{5}{|c|}{ Educational status of the father } \\
\hline No formal education & $16(13.2)$ & $31(8.5)$ & 1 & \\
\hline Primary (1-8) & $17(14.0)$ & $69(19.0)$ & $0.48(0.21,1.07)$ & 0.07 \\
\hline Secondary (9-12) & $50(41.3)$ & $162(44.6)$ & $0.59(0.30,1.18)$ & 0.14 \\
\hline College and above & $38(31.4)$ & $101(27.8)$ & $0.73(0.36,1.48)$ & 0.38 \\
\hline \multicolumn{5}{|l|}{ Occupation of the father } \\
\hline Farmer & $38(31.4)$ & $118(32.5)$ & $0.63(0.35,1.16)$ & 0.14 \\
\hline Merchant & $16(13.2)$ & $66(18.2)$ & $0.48(2.23,0.98)$ & 0.05 \\
\hline Government employer & $42(34.7)$ & $130(35.8)$ & $0.63(0.35,1.15)$ & 0.13 \\
\hline Other@ & $25(20.7)$ & 49 (13.5) & 1 & \\
\hline \multicolumn{5}{|l|}{ Place residence } \\
\hline Urban & 79 (65.3) & $266(73.3)$ & $0.69(0.44,1.07)$ & 0.09 \\
\hline Rural & $42(34.7)$ & $97(26.7)$ & 1 & \\
\hline \multicolumn{5}{|c|}{ The average income per month } \\
\hline$<35.4$ USD & $38(31.4)$ & $39(10.7)$ & 1 & \\
\hline 35.4-88.5USD & $67(55.4)$ & $232(63.9)$ & $0.29(0.18,0.50)$ & $<0.0001$ \\
\hline$>88.5$ USD & $16(13.2)$ & $92(25.3)$ & $1.18(0.09,0.36)$ & $<0.0001$ \\
\hline
\end{tabular}

${ }^{a}$ single, divorced and separated due to work, +Zayise, Amhara, Oromo, Gurage, Woliata, Konso, Derashe, Oyida and Gidicho, ${ }^{\circ d a i l y ~ l a b o r e r ~ a n d ~ s t u d e n t, ~}$ and@waiver and daily laborer

up and 121(100\%) had postnatal care for cases and $337(92.8 \%)$ and 363(100\%) for controls respectively. Regarding the mode of delivery, 57(47.1\%) gave birth by cesarean, and $64(52.9 \%)$ were by non-cesarean for cases, and 49(13.5\%), and 314(86.5\%) for controls respectively. Sixty-three (52.1\%) of the neonates' presentation during delivery was vertex for cases and 325(89.5\%) for controls (Table 3). 
Table 3 Maternal and child health and obstetric factors of study participants in selected hospitals of Gamo and Gofa Zones, Southern Ethiopia, 2018/9

\begin{tabular}{|c|c|c|c|c|}
\hline Variables & Cases $(n=121)$ & Controls $(n=363)$ & COR $(95 \% \mathrm{Cl})$ & $P$-value \\
\hline \multicolumn{5}{|l|}{ Party } \\
\hline Primipara & $20(16.5)$ & $167(46.0)$ & 1 & \\
\hline Multipara & $101(83.5)$ & $196(54.0)$ & $4.30(2.55,7.25)$ & $<0.0001$ \\
\hline \multicolumn{5}{|l|}{ ANC } \\
\hline Yes & $54(44.6)$ & $337(92.8)$ & $0.06(0.04,0.11)$ & $<0.0001$ \\
\hline No & $67(55.4)$ & $26(7.2)$ & 1 & \\
\hline \multicolumn{5}{|l|}{ Number of ANC visit } \\
\hline No visit & $67(55.4)$ & $26(7.2)$ & 1 & \\
\hline $1-3$ & $34(28.1)$ & $124(34.1)$ & $0.11(0.06,0.19)$ & $<0.0001$ \\
\hline$\geq 4$ & $20(16.5)$ & $213(58.7)$ & $0.04(0.02,0.07)$ & $<0.0001$ \\
\hline \multicolumn{5}{|l|}{ Hemorrhage } \\
\hline Yes & $8(6.6)$ & $6(1.7)$ & $4.21(1.43,12.39)$ & 0.009 \\
\hline No & $113(93.4)$ & $357(98.3)$ & 1 & \\
\hline \multicolumn{5}{|l|}{ Cause of Hemorrhage } \\
\hline$N A^{a}$ & $113(93.4)$ & $357(98.3)$ & $0.24(0.05,1.08)$ & 0.06 \\
\hline Placenta praevia & $4(3.3)$ & $3(0.8)$ & $1.00(0.12,8.31)$ & 1.00 \\
\hline Other ${ }^{\oplus}$ & $4(3.3)$ & $3(0.8)$ & 1 & \\
\hline \multicolumn{5}{|l|}{ Premature rupture of membrane } \\
\hline Yes & $63(52.1)$ & $41(11.3)$ & $8.53(5.27,13.82)$ & $<0.0001$ \\
\hline No & $58(47.9)$ & $322(88.7)$ & 1 & \\
\hline \multicolumn{5}{|l|}{ Hypertension during pregnancy } \\
\hline Yes & $24(19.8)$ & $25(6.9)$ & $3.35(1.83,6.12)$ & $<0.0001$ \\
\hline No & $97(80.2)$ & $338(93.1)$ & 1 & \\
\hline \multicolumn{5}{|l|}{ Classification of HTN } \\
\hline$N A^{a}$ & $97(80.2)$ & $338(93.1)$ & $0.22(0.05,0.98)$ & 0.05 \\
\hline Pre-eclampsia eclampsia syndrome & $20(16.5)$ & $22(6.1)$ & $0.68(0.14,3.43)$ & 0.64 \\
\hline Chronic hypertension & $4(3.3))$ & $3(0.8))$ & 1) & \\
\hline \multicolumn{5}{|l|}{ Mode of delivery } \\
\hline Cesarean & $57(47.1)$ & $49(13.5)$ & $5.71(3.58,9.10)$ & $<0.0001$ \\
\hline Non-cesarean \pm & $64(52.9)$ & $314(86.5)$ & 1 & \\
\hline \multicolumn{5}{|l|}{ Presentation } \\
\hline Vertex & $63(52.2)$ & $325(89.5)$ & 1 & \\
\hline Non-vertex@ & $58(47.9)$ & $38(10.5)$ & $7.87(4.82,12.85)$ & $<0.0001$ \\
\hline
\end{tabular}

${ }^{a}$ Not applicable, ${ }^{\oplus}$ postpartum hemorrhage, accreta/increta/percreta, hemorrhage during delivery, uterine rupture and other obstetric hemorrhages, \pm spontaneous vaginal delivery, and instrumental (assisted) delivery, and@breech, transverse, face and brow

\section{Factors associated with neonatal near-miss}

In the multivariable analysis of independent variables within conditional logistic regression model multiparty, ANC, premature rupture of membrane (PROM), nonvertex presentation and cesarean mode of delivery were significantly associated with NNM cases.

The odds of NNM were 3.81 among multiparous as compared to nulliparous $(\mathrm{AOR}=3.81,95 \% \mathrm{CI}$ : 1.72 , 8.42). A neonate's mother who had ANC follow up was $98 \%$ times less likely to have NNM cases as compared to mothers hadn't $(\mathrm{AOR}=0.02,95 \% \mathrm{CI}$ : $0.01,0.05)$. A neonate's mother who faced PROM before the onset of delivery was 3.40 times, and who gave birth by cesarean mode of delivery were 4.89 times more likely to have $\mathrm{NNM}$ cases $(\mathrm{AOR}=3.40$, 95\%CI:1.53, 7.55), and $(\mathrm{AOR}=4.89,95 \% \mathrm{CI}: 2.34$, 10.24) respectively. Neonates who had non-vertex presentation were $83 \%$ more likely to become nearmiss as compared to counterparts $(\mathrm{AOR}=2.83$, 95\%CI: 1.44, 5.58) (Table 4). 


\section{Discussion}

Identifying factors affecting neonatal near-miss cases is fundamental to condense neonatal mortality. Some studies were conducted in assessing neonatal near-miss cases, but they failed in identifying the most determinants for near-miss cases. Therefore, this study showed the most proximate factors affecting near-miss cases in the study settings.

Of the characteristics that were assessed in this study; multiparty, antenatal care, premature rupture of membrane, non-vertex presentation, and cesarean mode of delivery had a significant association with neonatal nearmiss cases.

As indicated in this finding multiparty was significantly associated with NNM. This was in line with a study done in Ethiopia [26], but inconsistent with a study done in Southeast Brazil [19]. This difference is maybe due to differences in socioeconomic status and health care delivery system. Not having ANC follow-up

Table 4 Multivariable analysis of the factors associated with neonatal near-miss cases in the conditional logistic regression model in selected hospitals of Gamo Gofa Zones, Southern Ethiopia, 2018/9

\begin{tabular}{|c|c|c|}
\hline Variables & Adjusted OR(95\%Cl) & $P$-value \\
\hline \multicolumn{3}{|c|}{ Educational status of the mother } \\
\hline Primary (1-8) & $1.89(0.53,6.76)$ & 0.33 \\
\hline Secondary (9-12) & $1.32(0.43,4.08)$ & 0.63 \\
\hline College and above & $1.19(0.34,4.23)$ & 0.79 \\
\hline \multicolumn{3}{|c|}{ Educational status of the father } \\
\hline Primary (1-8) & $0.42(0.13,1.44)$ & 0.17 \\
\hline Secondary (9-12) & $0.96(0.33,2.78)$ & 0.95 \\
\hline College and above & $0.79(0.26,2.41)$ & 0.69 \\
\hline \multicolumn{3}{|l|}{ Place residence } \\
\hline Urban & $0.73(0.35,1.54)$ & 0.41 \\
\hline \multicolumn{3}{|l|}{ Party } \\
\hline Multipara & $3.81(1.72,8.42)^{*}$ & 0.001 \\
\hline \multicolumn{3}{|l|}{ Antenatal care } \\
\hline Yes & $0.02(0.01,0.05)^{*}$ & $<0.0001$ \\
\hline \multicolumn{3}{|l|}{ Hemorrhage } \\
\hline Yes & $0.56(0.10,3.09)$ & 0.51 \\
\hline \multicolumn{3}{|c|}{ Premature rupture of membrane } \\
\hline Yes & $3.40(1.53,7.55)^{*}$ & 0.003 \\
\hline \multicolumn{3}{|c|}{ Hypertensive disorder during pregnancy } \\
\hline Yes & $1.08(0.34,3.45)$ & 0.89 \\
\hline \multicolumn{3}{|l|}{ Presentation } \\
\hline Non-vertex@ & $2.83(1.44,5.58)^{*}$ & 0.003 \\
\hline \multicolumn{3}{|l|}{ Mode of delivery } \\
\hline Cesarean & $4.89(2.34,10.24)^{*}$ & $<0.0001$ \\
\hline
\end{tabular}

had a significant factor for having neonates with a lifethreatening condition (near-miss) as point outed in this study. This was congruent with a study done in Southeast Brazil [19]. This is obvious that the pregnant mother avoids preventable risk factors after having ANC follow and early identification, and treatment of preexisting conditions, and early screening of conditions that occurred during pregnancy.

Premature rupture of membrane and cesarean mode of delivery were significantly associated with NNM cases in this finding. This was in line with studies done in South Africa, and three studies in Brazil [15, $16,19,27]$. The reason for this is that those stated conditions are one, or in another way can affect the neonates during intra-uterine as well as extra-uterine life and predispose for life-threatening conditions. In this study, the non-vertex presentation had a significant association with NNM cases. This is the fact that mal-presentation during delivery cause different complications in the mother as well as in the baby, and results for neonatal near-misses.

In this study, hemorrhage and hypertensive disorder during pregnancy were not significantly associated with neonatal near-miss cases. This was incongruent with a study done by Kale et al. [19]. The reason for this discrepancy may be methodological aspects of the study (difference in the study participant selection, study setting, and design). Educational status of the mother and father and place of the residence had also not significate association with neonatal near-miss cases as speculated in this finding. This is because, nowadays there is an improvement in the health care delivery system, advances in technology, and seeking health information irrespective of residence and educational status.

The utmost importance of this study for public health is: identifying the potential factors that predispose the newborn for life-threatening (near-miss) conditions are very important to tackle the underlining causes and to give immediate solutions. The finding of this study initiates different stakeholders in the health care system to design appropriate strategies and planning for the measurements to be taken to avoid those potential factors, both in the health care institutions as well as in the community at large. This study becomes one input for health policymakers and program developers typical regarding neonatal health in the health care delivery system.

The limitation of this study is that it does not incorporate some of the variables that are addressed in the community, such as wealth index, nutritional status, and cultural aspects. Therefore, other scholars should consider those situations and it also very important if they supplement or triangulate with a qualitative study to dig out untouched aspects. 
The strength of this study was that data on exposure and confounding collected before the occurrence of cases (neonatal near-miss case) (from the follow-up study conducted in the same setting), which reduces the potential for recall bias and uncertainty regarding the temporal sequence between exposure and case onset. Besides, it was more efficient to measure the exposure status as compared to the whole cohort.

In summary, there is a gap in previous studies to show the most proximate factors that affect neonatal nearmiss cases. Therefore, this study envisioned to fill the aforementioned gaps. In this study, party, antenatal care, premature rupture of membrane, presentation, and mode of delivery were significantly associated with nearmiss cases. Whereas, the educational status of the mother and father, place of residence, hemorrhage, and hypertensive disorder during pregnancy had not significate association with near-miss cases. The readers should consider the limitations of this study while interpreting the finding, and the other scholars will do more to overcome those limitations. The finding of this study gives an overriding reputation to tackle factors affecting neonatal health, which leads to near-miss and predisposing factors for neonatal mortality.

\section{Conclusions}

Multiparty, not having antenatal care follow up, premature rupture of membrane, non-vertex presentation, and cesarean mode of delivery were the independently associated factors with neonatal near-miss cases. Strengthening antenatal care services by providing appropriate information for the mother, and counseling about the consequences of multiparty and providing information on family planning for those mothers. There is a need to identify, screen and critical follow high-risk mothers: those who had different complications during pregnancy, those who faced premature rupture of membrane, those who identified as the fetal presentation was non-vertex, and those undergoing cesarean section due to different indications.

\section{Supplementary information}

Supplementary information accompanies this paper at https://doi.org/10. 1186/s12884-019-2684-x.

Additional file 1. English version questionnaire (pdf)

\section{Abbreviations}

ANC: Antenatal care; NICU: Neonatal intensive care unit; NNM: Neonatal near-miss; PROM: Premature rupture of membrane

\section{Acknowledgments}

My unreserved thank goes to Arba Minch University, College of Medicine and Health Sciences, Research Coordination Office, which gave me a chance to do this research project and fully funded for this research work. I would like to forward my deepest appreciation and thanks to Gamo and Gofa
Zones Health Department workers, CEOs, medical directors, and health care providers of three hospitals in the zones (Arba Minch General Hospital, Sawla General Hospital, and Chencha Primary Hospital), data collectors, and study participants. Last but not least, I would like to say thank you to all peoples who support directly or indirectly.

\section{Authors' contributions}

AM designed the study, involved in data collection, done the analysis and interpretation of the result and drafted the paper and participated in preparing all versions of the manuscript. AB and SS assisted in the design and the proposal development, monitored data collection, assisted during analysis and revised subsequent drafts of the paper. All authors read and approved the final manuscript.

\section{Authors' information}

Abera Mersha (BScN, MSc in Maternity and Neonatal Nursing), Department of Nursing, College of Medicine and Health Sciences, Arba Minch University, Arba Minch, Ethiopia.

Agegnehu Bante (BSCN, MSc in Maternity and Neonatal Nursing),

Department of Nursing, College of Medicine and Health Sciences, Arba Minch University, Arba Minch, Ethiopia.

Shitaye Shibiru (BSCN, MSC in Maternity and Reproductive Health Nursing), Department of Nursing, College of Medicine and Health Sciences, Arba Minch University, Arba Minch, Ethiopia.

\section{Funding}

Arba Minch University provided funds for the data collection and stationary materials of this research work with a project grant code of GOV/AMU/ TH.1.1/CMHS/NUR/04/10. The website of the university is www.amu.edu.et. The funding institution had no part in study design, information gathering, and analysis, judgment to publish, or development of the manuscript.

Availability of data and materials

The data will not be shared to preserve participant anonymity.

Ethics approval and consent to participate

Ethical clearance was obtained from Arba Minch University, College of Medicine and Health Sciences, Institutional Research Ethics Review Board (IRB). Adequate explanation about the purpose of the study and a letter of support was given to Gamo and Gofa Zones Health Departments and CEOs of each hospital. After stating the purpose of the study and their right to refuse participation, written informed consent was obtained from all respondents (parents/guardians) before actual data collection. The study participants were also well-versed that the data gained from them were kept with greater trustworthy.

Consent for publication

Not applicable.

\section{Competing interests}

All principal investigators of this study affirm that they have no competing interests.

Received: 9 August 2019 Accepted: 17 December 2019

Published online: 21 December 2019

\section{References}

1. SDG, Sustainable Development Goal 3: Ensure healthy lives and promote well-being for all at all ages. Progress of goal 3 in 2017. Reproductive, maternal, newborn and child health, 2017. Available at: https://www.who. int/sdg/targets/en/. Accessed 6 Sep 2017.

2. UNICEF, UNICEF Data: Monitoring the Situation of Children and Women, 2016. Available at: <https://data.unicef.org/topic/child-survival/neonatalmortality/>. Accessed 6 Sep 2017.

3. UNICEF, Maternal and newborn health, 2008. Available at: https://www. unicef.org/protection/SOWC09-FullReport-EN.pdf. Accessed 29 Oct 2017.

4. WHO. To reduce child mortality. 2016. Available at: http://www.who.int/ mediacentre/factsheets/fs178/en/. Accessed 27 Jun 2017.

5. WHO. Global Health Observatory $(\mathrm{GHO})$ data. Neonatal mortality, World Health Statistics data visualizations dashboard, 2018. Available at: http:// apps.who.int/gho/data/node.sdg.3-2-data?lang=en. Accessed 2 Dec 2018. 
6. Unicef. Levels \& Trends in Child Mortality. Report 2014. New York: United Nations Children's Fund, 2014. Available at: http://www.unicef.org/media/ files/Levels_and_Trends_in_Child_Mortality_2014.pdf. Accessed 23 Aug 2017.

7. Warren C, Daly P, Toure L, Mongi P. Opportunities for Africa's Newborns: Postnatal care, 2015. Available at: http://www.who.int/pmnch/media/ publications/aonsectionlll_4.pdf. Accessed 23 Sep 2019.

8. USAID, USAID Combats Maternal, Neonatal and Child Mortality in Ethiopia, 2016. Available at: <http://borgenproject.org/usaid-fights-child-mortalityethiopia/>. Accessed 22 Jun 2017.

9. Ethiopian Public Health Institute (EPHI) [Ethiopia] and ICF. Ethiopia mini demographic and health survey 2019: key indicators. Rockville, Maryland, USA: EPHI and ICF; 2019.

10. Pileggi C, Souza JP, Cecatti JG, Faundes A. Neonatal near-miss approach in the 2005 WHO Global Survey Brazil. J Pediatr (Rio J). 2010;86(1):21-6.

11. Nakimuli A, Mbalinda SN, Nabirye RC, Kakaire O, Nakubulwa S, Osinde MO, Kakande N, Kaye DK. Stillbirths, neonatal deaths and neonatal near-miss cases attributable to severe obstetric complications: a prospective cohort study in two referral hospitals in Uganda. BMC Pediatr. 2015;15:44

12. Pileggi-Castro C, Camelo JS, Perdona GC, Mussi-Pinhata MM, Cecatti JG, Mori R, Morisaki N, Yunis K, Vogel JP, Tuncalp O, Souza JP. Development of criteria for identifying neonatal near-miss cases: analysis of two WHO multicountry cross-sectional studies. BJOG. 2014;121(Suppl 1):110-8.

13. Santos JP, Pileggi-Castro C, Camelo JS, Silva AA, Duran P, Serruya SJ, Cecatti JG. Neonatal near-miss: a systematic review. BMC Pregnancy Childbirth. 2015:15:320.

14. Santos JP, Cecatti JG, Serruya SJ, Almeida PV, Duran P, Mucio BD, PileggiCastro C. Neonatal near-miss: the need for a standard definition and appropriate criteria and the rationale for a prospective surveillance system. Clinics (Sao Paulo). 2015;70(12):820-6

15. Avenant T. Neonatal near-miss: a measure of the quality of obstetric care. Best Pract Res Clin Obstet Gynaecol. 2009;23(3):369-74.

16. Silva AA, Leite AJ, Lamy ZC, Moreira ME, Gurgel RQ, Cunha AJ, Leal MC. Neonatal near-miss in the birth in Brazil survey. Cad Saude Publica. 2014; 30(Suppl 1):S1-10.

17. Bushtyrev VA, Bushtyreva IO, Kuznetsova NB, Budnik ES. Audit of neonatal near-miss: possibilities of improving in perinatology polymorphisms. Obstet Gynecol. 2016;7:79-82.

18. Manandhar S, Manandhar D, Adhikari D, Shrestha J, Rai C, Rana H, Paudel M. Neonatal near miss cases of different health facilities. J Nepal Paediatr Soc. 2014;34(2):115-8.

19. Kale PL, Mello-Jorge MHP, Silva KSD, Fonseca SC. Neonatal near-miss and mortality: factors associated with life-threatening conditions in newborns at six public maternity hospitals in Southeast Brazil. Cad Saude Publica. 2017; 33(4):e00179115.

20. Debelew GT, Afework MF, Yalew AW. Determinants and causes of neonatal mortality in Jimma Zone, Southwest Ethiopia: a multilevel analysis of prospective follow up study. PLoS One. 2014;9(9):e107184.

21. USAID, Maternal, Neonatal and Child Health, 2017. Available at: https:// www.usaid.gov/ethiopia/global-health/maternal-and-child-health. Accessed 16 Sep 2017.

22. Federal Democratic Republic of Ethiopia Central Statistical Agency. Population Projection of Ethiopia for All Regions: At Wereda Level from 2014-2017, Addis Ababa, Ethiopia, 2013. Available at: https://www. academia.edu/30252151/Federal_Democratic_Republic_of_Ethiopia_ Central_Statistical_Agency_Population_Projection_of_Ethiopia_for_All_ Regions_At_Wereda_Level_from_2014_2017. Accessed 20 Sep 2017.

23. Gamo Gofa Zone health bearue department report, 2007 EC.

24. de Lima THB, Katz L, Kassar SB, Amorim MM. Neonatal near miss determinants at a maternity hospital for high-risk pregnancy in northeastern Brazil: a prospective study. BMC Pregnancy Childbirth. 2018;18:401.

25. Near-miss and quality of care tool. Available at: http://www.abdn.ac.uk/ femhealth/. Accessed 10 May 2019].

26. Nugussie F, Alemayehu MG, Mariam KA. Case-control study examining determinants of neonatal near-miss in public hospitals in Tigray region, northern Ethiopia. Research \& Reviews. J Med Sci Technol. 2018;7(3):1-11.

27. Silva GA, Rosa KA, Saguier ESF, Henning E, Mucha F, Franco SC. A populational based study on the prevalence of neonatal near-miss in a city located in the South of Brazil: prevalence and associated factors. Rev. Bras. Saude Mater. Infant. 2017;17:159-167.

\section{Publisher's Note}

Springer Nature remains neutral with regard to jurisdictional claims in published maps and institutional affiliations.
Ready to submit your research? Choose BMC and benefit from:

- fast, convenient online submission

- thorough peer review by experienced researchers in your field

- rapid publication on acceptance

- support for research data, including large and complex data types

- gold Open Access which fosters wider collaboration and increased citations

- maximum visibility for your research: over $100 \mathrm{M}$ website views per year

At BMC, research is always in progress.

Learn more biomedcentral.com/submissions 